\title{
Erratum to: Repetitive Thought and Emotional Distress: Rumination and Worry as Prospective Predictors of Depressive and Anxious Symptomatology
}

\author{
Christine A. Calmes $\cdot$ John E. Roberts
}

Published online: 17 March 2012

(C) Springer Science+Business Media, LLC 2012

\section{Erratum to: Cogn Ther Res (2007) 30:343-356 DOI 10.1007/s10608-006-9026-9}

The article, "Repetitive thought and emotional distress: Rumination and worry as prospective predictors of depressive and anxious symptomatology" by Calmes, C.A. and Roberts, J.E., published in the June 2007, Volume 30 (3) issue of Cognitive Therapy and Research, includes a correlation matrix (Table 1) that was based on variables from an earlier draft that used Structural Equation Modeling (SEM) with three indicators per construct created from parcels of items from each measure. In response to reviewer feedback, the published article used SEM with single indicators rather than parcels, but Table 1 was not updated to reflect this change in analytic procedures. The correct table is presented here.

Table 1 Correlations, means, and standard deviations among all measured variables

\begin{tabular}{|c|c|c|c|c|c|c|c|c|c|}
\hline & BDI T1 & BDI T2 & BAI T1 & BAI T2 & RUM T1 & RUM T2 & Worry T1 & Mean & SD \\
\hline BDI T1 & & & & & & & & 13.9 & 9.5 \\
\hline BDI T2 & .76 & & & & & & & 12.7 & 10.0 \\
\hline BAI T1 & .60 & .54 & & & & & & 14.5 & 10.3 \\
\hline BAI T2 & .52 & .63 & .67 & & & & & 13.3 & 11.4 \\
\hline RUM T1 & .61 & .50 & .50 & .45 & & & & 48.7 & 13.0 \\
\hline RUM T2 & .57 & .55 & .48 & .52 & .75 & & & 47.1 & 13.2 \\
\hline Worry T1 & .57 & .48 & .52 & .49 & .49 & .48 & & 29.8 & 10.8 \\
\hline Worry T2 & .55 & .53 & .49 & .56 & .49 & .58 & .79 & 28.6 & 11.0 \\
\hline
\end{tabular}

All correlations are statistically significant at $p<.01$

$B D I$ Beck depression inventory, BAI Beck anxiety inventory, RUM rumination, $T 1$ time 1, $T 2$ time 2, $S D$ standard deviation

The online version of the original article can be found under doi:10.1007/s10608-006-9026-9.

C. A. Calmes - J. E. Roberts

Department of Psychology, University at Buffalo,

The State University of New York, Buffalo, NY, USA

J. E. Roberts $(\bowtie)$

Department of Psychology, University at Buffalo,

The State University of New York, Buffalo, NY 14260, USA

e-mail: robertsj@buffalo.edu 